Claudia Padovani, ${ }^{*}$ Karen Ross**

\title{
Advancing gender equality in media industries: an innovative european approach
}

\section{Impulsando la igualdad de género en las industrias de medios de comunicación: una aproximación europea innovadora}

\begin{abstract}
Most people recognise that mainstream media industries are important players in contemporary societies, simultaneously galvanizing change through cutting-edge programming and technological development but also reinforcing long-standing inequalities and discrimination through the perpetuation of stereotypes in content and restricting career opportunities. When we consider the specific issue of gender and media and their inter-relationship, numerous research studies over the past 50 years have demonstrated persistent problems in terms of disrespectful representations of women, routine inequalities within the workplace and unequal gendered power relations in management structures (Tuchman et al. 1975; Gallagher 1995; Rush et al. 2005; Byerly 2011; North 2015; Ross \& Padovani 2016). These issues serve to constrain societal progress and make the goal of gender justice extremely hard to achieve.
\end{abstract}

Keywords I gender, media industries, Europe.

Resumen | La mayoría de las personas reconoce que las industrias mediáticas dominantes son actores importantes en las sociedades contemporáneas, impulsando simultáneamente el cambio a través de programación y desarrollo tecnológico de vanguardia, pero también reforzando las desigualdades y discriminación de larga data a través de la perpetua-

Recibido: 16 de enero de 2018.

Aceptado: 18 de junio de 2018.

* Professor and researcher on Politic Sciences and International Relations at the SPGI at the University of Padova.

$* *$ Newcastle University. Karen Ross researches and teaches media, gender and political communication, writes about gender, politics, news and representation and is currently Professor of Gender and Media in the School of Arts and Cultures, Newcastle University. She has held positions as Visiting Professor in the School of Communication and Journalism at Massey University (2007-2011) and the Centre for Advancement of Women in Politics at Queens University Belfast (2001-2004). She will be a Distinguished Visitor at Massey University in 2018.

Correos electrónicos: claupad67@gmail.com | karen.Ross@newcastle.ac.uk

Padovani, Claudia, Karen Ross «Advancing gender equality in media industries: an innovative european approach.» Interdisciplina $7, \mathrm{n}^{\circ} 17$ (enero-abril 2019): 87-98. DOI: http://dx.doi.org/10.22201/ceiich.24485705e.2019.17.67521 
ción de estereotipos en el contenido y la restricción de oportunidades laborales. Cuando consideramos el tema específico del género y los medios y su interrelación, numerosos estudios de investigación en los últimos 50 años han demostrado problemas persistentes en términos de representaciones irresponsables de las mujeres, desigualdades de rutina en el lugar de trabajo y relaciones desiguales de poder de género en la gestión de estructuras (Tuchman et al. 1975; Gallagher 1995; Rush et al. 2005; Byerly 2011; North 2015; Ross \& Padovani 2016). Estos problemas sirven para restringir el progreso social y hacer que el objetivo de la justicia de género sea extremadamente difícil de lograr.

Palabras clave I género, industrias de medios, Europa.

THE MEDIA, both as an important economic sector and as social and cultural institutions, can only work towards the goal of gender equality in the wider society if they recognise and act on the persistent equality issues within their own sector and in order to do this, the sector needs interventions at the educational, cultural and organizational level. A number of such interventions have been developed and implemented internationally over the past years, including in response to policy recommendations coming from the United Nations and from European and other regional institutions. Good practices have been put in place with a view not only to transforming the internal operations of media organisations towards a more gender-sensitive working environment, but also in response to the media's wider responsibility towards the society it purports to serve. But these good practices mostly remain at the level of individual initiatives, their impact and benefits remaining largely unknown outside the promoting organisations themselves.

There have been several previous attempts to bring together resources focused on the gender-media relationship, most of which include recommendations for action and examples of good practices in the sector. The European Institute for Gender Equality, the Council of Europe, the EU Advisory Committee on Equal Opportunities for Women and Men, as well as a number of professional and civil society organizations such as the International Federation of Journalists and initiatives such as the Global Media Monitoring Project, ${ }^{1}$ have all produced handbooks or databases of good practices or research reports, but they remain scattered and not always easy to find, nor have they been extensively promoted or disseminated. There is therefore a need to bring these rich resources together in one place in order to maximize their impact and influence in order to promote change and this article introduces a new project which is doing exactly that. 


\section{The Project - Overview}

The Advancing Gender Equality in Media Industries (AGEMI) ${ }^{2}$ Project takes an innovative and integrated approach to combating gender stereotypes and promoting equal opportunities, by designing educational and knowledge-based resources aimed at inspiring and informing students as well as media professionals. By raising awareness of both the problems of gender in/equality in the media but also the range of initiatives which have been created to challenge them, media and journalism students and colleagues already working in the industry, will be encouraged to develop a gender-sensitive professional practice. The Project is funded by the European Union, runs from February 2017 to July 2019 and is being developed by a consortium led by Newcastle University and also comprising the Universities of Padova and Gothenburg, the European Federation of Journalists and the Permanent Conference of Public Broadcasters in the Mediterranean (COPEAM).

As educators of journalism and media students and associations of media professionals, the AGEMI Project team members recognise that there is sometimes a mismatch between what we teach our students and what the industry expects from graduates; and students often have an unrealistic understanding of their chosen profession. The challenging economic environment and shifts in production practices are transforming the media industry as an economic sector with increasing casualization and the retrenchment of both vertical and horizontal segregation along gendered lines operating alongside new opportunities for women (and men) enabled by the rapid development of digital technologies. There is therefore a need to bridge the existing gap between educational institutions and the media as an employing sector, and to enable students to experience the real world of work in order to both understand the realities of an everchanging media environment but also the challenges of promoting a gender-sensitive professional practice in a highly time-pressured and demanding context.

The Project thus brings students into direct contact with media professionals in order to bridge the education-employment transition in ways which enable mutual learning through knowledge exchange and transfer events such as summer schools and internships. In this way, students gain experiences which will help their employability as well as entering their chosen profession as women and men with a concrete and operational understanding of how to challenge gender inequalities. For their part, media professionals have an opportunity to input directly to the education and training of the next generation of potential

2 This Project is co-funded by the Rights, Equality and Citizenship Programme of the European Union. 
colleagues. This approach maximizes the potential for transformative changes in attitudes (through awareness-raising), behavior (through professional practice) and culture (through sharing and implementing good practices).

Project objectives, to:

- raise awareness of gender inequalities amongst media and journalism students and the good practices which challenge them, so as to break the cycle of gender-stereotyping through a commitment to and promotion of a gender-sensitive and equality-focused professional practice;

- promote and share the good practices which have been developed in media industries in Europe and around the world, but which largely remain known only within the confines of the media organisations to which they belong, through their inclusion in an openly accessible Online Knowledge Platform;

- maximize the potential for existing good practices to change behavior and attitudes amongst all relevant stakeholders by developing a typology and framework under which the good practices will be organized in a repository (Resource Bank), together with short profiles of key examples;

- bridge the transition between education and employment though transnational encounters between students, educators and media professionals through a summer school and internships, focused on the transformative potential of good practices and promoting student employability, and

- develop gender-aware learning and teaching materials which are relevant to the media industry through their cocreation by media educators and professionals, which maximize the potential for attitudinal, behavioral and cultural change in the media sector.

At the time of writing, AGEMI has been running for sixteen months and the remainder of this article focuses on one of the primary objectives: to develop a Resources Bank of Good Practices.

\section{Good Practices, Good News: the AGEMI Resources Bank}

We designed AGEMI having in mind the ultimate goal of the European Commission in issuing the call to which the Project Team responded with our proposal for AGEMI: "to overcome gender stereotypes in education, training and in the workplace by promoting existing good practices on gender roles". We therefore translated those words into something that would resonate with the Project team's understanding of how to build a lively, globally-active and transforma- 
tive gender and media environment. As we have already observed, many years of research in the field have shown the persistence of gender inequalities, but we have also learned that inequalities have been addressed, in creative and influential ways, through initiatives organized by media professionals themselves as well as by civic organizations, public institutions, and universities.

We have also come to realize that, although social and cultural differences characterize both the diverse contexts of gender-media discrimination as well as the initiatives designed by different actors to address them, there seem to be some common lines of reasoning running through advocacy initiatives. They are often connected - conceptually and practically - through international encounters like the highly influential 1995 Fourth World Conference on Women held in Beijing which prompted the Beijing Platform for Action on gender equality, the Commission on the Status of Women (CSW) annual conferences, and long-standing and longitudinal transnational projects such as the Global Media Monitoring Project (GMMP 1995-2015).

Despite this, it seems that very little of this diverse and rich reality is actually understood by a wider audience: initiatives remain known mostly to those involved in their production and confined to the context where they were deployed. There are no widely-used communication channels through which relevant information about such change-making initiatives can be routinely and easily disseminated, nor is there a single place where interested individuals be they media professionals or communication and journalism teachers-can look for suggestions on what good practices have been developed or how they could be appropriated or re-purposed for other environments. The good news is that there is a multiplicity of good practices being elaborated and implemented across the world and it is also true that good practices actually contribute to good (better) news (and news-making). So we asked ourselves, could we contribute to making the world's media 'good' in terms of gender-responsiveness if we enabled a meaningful number of such good practices to be connected transnationally and widely known? In other words, could we devise an initiative which could tell a good-news story and contribute towards make better-news stories in the future?

We realized that addressing these issues of fragmentation would allow the creativity, insight and energy that generated all those activities to be globally valued and made accessible to a plurality of interested actors. We therefore decided that a core component of the AGEMI Project would be the creation of a database of good practices which had (or hoped to have) enhanced gender equality in the media in some way, from around the world and across all media types, from newspapers and television to social media platforms and including public, private and civil society organisations. We envisaged a collection - and poten- 
tially a 'connector' - of good practices organized so that different interested publics could find concrete ideas and examples to develop their own strategies to address gender-based discrimination. This would be a 'one-stop shop' that would contribute to a better understanding of transformative practices and the circumstances in which they could thrive, thus favoring a good news outcome while, at the same time, allowing us to consider such initiatives as indicators of a wider media gender-equality advocacy movement.

The result will be what we have described as a Resources Bank of Good Practices, one of the primary objectives of the AGEMI Project. So far, we have taken several steps down the path of creating such Resources Bank. ${ }^{3}$ We began by elaborating an operational definition of 'good practice' in the gender and media context for two reasons. First, we felt that conceptual clarification was needed in relation to the term 'good practice', since it is widely used but seldom specified. Secondly, we believe that the media sector is characterized by specific features that need to be taken into consideration. Thus, our working definition of the term 'practice' in relation to initiatives around improving gender equality became:

[...] any experience, initiative or provision displaying techniques, methods or approaches which aims to improve or enhance gender equality in the media, understood as a condition where women and men enjoy equal rights, responsibilities and opportunities in the media and communication environment.

We then had to consider, what makes a practice 'good'? In response to this question, and in order to make the Project's procedures for inclusion of initiatives and activities completely transparent to future users of the Resources Bank, we elaborated a set of criteria according to which initiatives could be regarded as 'good'. So for us, a practice is regarded as 'good' if it has run at least once (in other words, it must have been implemented) and meets at least two of the other criteria we devised: Has the practice worked well? Has it been transfor-

3 This was undertaken with due consideration to similar efforts that have been made at the international level, in particular in the European context by the European Institute for Gender Equality (EIGE). Since this is an European-based project, we deem it crucial to develop a resource that resonates with on-going efforts by European institutions to promote a gender-sensitive culture across all sectors of society, including through sharing and disseminating good practices. It should nevertheless be stated that the scope and potential outcome of the AGEMI Project has relevance considerably beyond the region: gender inequalities and media issues are global concerns and responses have been and are being undertaken in different geo-cultural contexts. Learning from those diverse experiences will enrich the understanding of how to make media more gender-responsive across the world and we believe that a collection of good practices that includes examples from every region will make the AGEMI Resources Bank a truly meaningful global resource. 
mative? Has it proven its capacity to improve gender equality in the sector? Is it transferable and adaptable to other contexts, showing a multiplying potential for change? Does the good practice have a learning potential and help foster new ways of thinking, within the media and in relation to the wider public? Moreover, we believe that good practices are particularly meaningful if they are not stand-alone initiatives, but are rather part of wider plans created to achieve gender equality, or if they are linked to existing strategies. We also believe that good practices are those initiatives capable of engaging a variety of interested stakeholders. It is particularly important within media organizations to engage senior managers but it is also important to involve non-media actors such as civic society organisations and consumer groups, schools and universities: the more diverse the stakeholders, the wider and deeper the potential for change. Finally, a practice is considered positive if it contributes to strengthen existing policy frameworks or lead to new policy developments, either for one organization or the sector in general. Indeed, linking transformative practices to policy developments can lead to formal commitments which are crucial to guarantee sustainability over time.

Another issue which we addressed early on was how to make sense of, and cluster the wide range of initiatives that have been designed and implemented to redress gender inequalities, from monitoring media content to mentorship, training and advocacy campaigns. We therefore developed a typology of good practices, which was then used to structure the collection and facilitate navigating the Resources Bank. Monitoring activities are wide-ranging and can be undertaken internally (in-house) or by external monitors including NGOs, often with the involvement of gender equality experts. Monitoring activities should have a clearly defined purpose, be conducted on a regular basis and results should be reported. They will often focus on media content but can also look at women's participation and expression in and through the media, as well as women's access to managerial and decision-making roles or other aspects. Another type of good practice is awareness-raising activities, usually focused on information-giving about gender and in/equalities through events such as conferences, workshops, tool-kits and manuals. Related to this are good practices focused on training and education, most of which are expected to have a clearly-defined purpose and comprise a set of activities that involve trainers and educators with gender expertise. They can be targeted at students as well as media practitioners.

The Resources Bank will also include examples of gender equality policies and plans adopted by media organizations as well as legal and policy frameworks elaborated at the national level, by governmental institutions or regulatory communication authorities. The former -including equality plans or codes of 
conduct, as well as support mechanisms such as monitoring procedures, equality officers, councils and departments - show the commitment of a media organization in fostering gender equality. The latter - both national media policies that make explicit reference to gender issues and gender strategies that incorporate roles and responsibilities of the media - set out the fundamental principles according to which gender-responsive communication systems should operate and indicate courses of action towards realizing those principles. Yet other types of good practices are all those initiatives which enable women's views, voices and expertise to be expressed, heard or seen, such as advocacy websites, women's news blogs, women's magazines and press agencies. Finally, we have included networking initiatives, promoted at local, national or transnational levels, which foster collaboration within and between media organizations, professional associations, and civic groups to increase gender equality. These may be considered as 'support' or 'enabling actions' and often help to share knowledge about existing good practices that tackle specific issues of inequality and discrimination.

Furthermore, the AGEMI Project is grounded in an articulated understanding of gender inequalities and the ways in which they have been challenged through the development and adoption of good practices. The Resources Bank will therefore include thumbnails of initiatives that tackle issues of unequal representation, such as actions to enhance non-stereotyped portrayal or to foster a balanced presence of women and men on screen and across other traditional media content; but also online content which reflects diversity of culture and languages; and fair coverage of gender equality issues. It will also include initiatives which encourage equal access to the media and ICTs and access to expression (voice), by promoting gender equality in media industries, unions and professional bodies; and encouraging women and men's involvement in decision-making structures, boards and independent regulatory authorities. It is also important to understand the media as a working environment: in this case, good practices may take the form of initiatives to promote equal treatment and recognition of competence in the workplace; encourage women into sectors which are traditionally male-dominated; breaking through glass ceilings and sticky floors; improving work-life balance and sharing family responsibilities; and/or fostering career development activities through leadership training, mentoring, buddy systems, career workshops and job shadowing.

They may also specifically address existing gender pay gaps, for instance by undertaking gender pay audits or follow-up actions to remedy gender-based inequalities in economic treatment and access to resources. Good practices may also address inequality issues by engaging with the creation, design and implementation of adequate legal and policy frameworks, from the adoption of self- 
regulatory mechanisms and professional codes of conduct, to the development and application of national indicators, to enforcing complaint mechanisms against media content which is offensive to women and/or men. They will also concern the production and dissemination of new knowledge through information sharing, research and education, including efforts to produce sex-disaggregated statistics and relevant indicators and developing educational and training materials which aim to develop awareness-raising of gender inequalities among diverse audiences including students, educators and media professionals. Finally, given the diffuse forms of harassment and abuse that characterize the contemporary media environment, the Resources Bank will include examples of activities which challenge gender-based violence of all types perpetrated in the media workplace as well as strategies which combat online gender-based violence against media professionals.

The conceptual structure we have developed for the Resources Bank which informs the collection and organization of the materials to be displayed in this openly accessibly database, ${ }^{4}$ will translate into profiled good practice, each narrated through: a) general information (title, short description, promoting entity/ies); b) information that locates the initiative in time and space (geographical location of initiative/promoting entity, period when it was/is being implemented, scope (referring to the breadth of the initiative and potential beneficiaries); and, c) specific information concerning the criteria according to which each good practice has been selected for inclusion in the database, the type of good practice, the issue/s it addresses and the stakeholder/s involved.

It is against the background of the foregoing discussion and description, that the AGEMI Resources Bank is being implemented. We have profiled some important and well-known examples such as the Global Media Monitoring Project, together with a range of initiatives which have been suggested by members of the Project team. We have also created profiles for good practices which appear in other collections ${ }^{5}$ and a range of research and policy reports. ${ }^{6}$

4 The Resources Bank will be available online to any interested individual and organization, as an openly accessible, easy-to-navigate collection. Knowing that many initiatives may not be included in the early version and many more could be included in the future, we also plan to develop the Resources Bank as an on-going collective resource, which may grow and be enriched even after the end of the Project. Sustainability is always an issue with these kind of projects, but we trust the relevance of the Resources Bank will facilitate transnational and transectorial collaborations that will allow it to become an autonomous space for knowledge-transfer and information-sharing.

5 In particular, those elaborated by the EIGE $(2013,2014)$, the IFJ (2012), and Edström and Molster (2014).

6 WACC (2015), Council of Europe (2014, 2015), EU Parliament (2013). 
As it evolves, the Resources Bank will benefit considerably from the collective knowledge of the many individuals involved in gender and media-related work, from academic researchers to professional associations and NGOs. Through reaching out for collaborators and engaging interested people and organizations worldwide, the Resources Bank will become a networking tool in its own right. In the summer and fall of 2017, we circulated a global and multilingual call for collaboration ${ }^{7}$ involving, amongst others, academic organizations like the International Association for Media and Communication Research (IAMCR) and the European Communication Research and Education Association (ECREA), as well as transnational networks like the UNESCO-promoted Global Alliance for Media and Gender (GAMAG) and the Association for Progressive Communication (APC).

This outreach activity aimed to not only gather a substantial number of examples from around the world, but also to make AGEMI widely known and generate an audience for the Resources Bank and the other materials which the Project will produce. The Resources Bank will be a globally-accessible, easy-toconsult, shared (and shareable) resource that will support transformative actions in the media industry. It will also benefit from a continuous process of enriching and extending the database through the ongoing addition of more examples. In this way, by keeping content refreshed and up-to-date, we hope to develop a follow-on funding strategy which will ensure the sustainability of the Project beyond 2019, thus becoming a global good practice in itself.

At the time of writing, the call for collaboration remains open ${ }^{8}$ and the interface of the Resources Bank is being finalized. The Project has now moved into its next phase, developing a set of online educational resources, comprising thematic units which will discuss a range of gender inequality issues and linking them to the good practices collected in the Resources Bank. Each unit will include video tutorials, lecture notes, interviews with experts, advocates and policy-makers, and a range of student activities. The outcome of this second core component of the AGEMI Project will be a freely-accessible Online Educational

7 It should be noted that the European call did not include any good practice global mapping exercise. This specific development came in the course of developing the Resources Bank and through an awareness that several networks to which the AGEMI Project team members were linked could constitute a very fruitful channel through which engaged people may be brought into the Project logic and activity. We count on the collective energy of such transnational networks to reach out to people who are creating, designing and implementing good practices and who see the relevance of making these initiatives more widely-known to a global audience of other interested individuals. In this manner we may create a much richer and more meaningful collection of useful materials and examples.

8 Anybody who is willing to contribute and suggest good practices to be included, can contact the Project at agemi_eu@gmail.com; or fill in the google form available at: https:// goo.gl/rnZxDC. 
Module -including materials available in English, French and Spanish- which will raise and spread awareness of gender-based inequalities in the media and of the many strategies which have been developed to challenge them. Id

\section{References}

Byerly C. M. Global report on the status of women in news media (technical report). Washington DC: International Women's Media Foundation, 2011.

Council of Europe. Gender equality and the media at national level. Compilation of good practices from Member States. Council of Europe, 2014.

Council of Europe Gender Equality Commission. Handbook on the implementation of Recommendation CM/Rec (2013)1 of the Committee of Ministers of the Council of Europe on Gender Equality and Media. Council of Europe, 2015.

Edström, M. and Molster, R. Making change. Nordic examples of working towards gender equality in the media. Gothenburg: Nordicom, 2014.

European Institute for Gender Equality. Review of the implementation of the Beijing Platform for Action in the EU Member States: Women and the media: advancing gender equality in decision-making in media organisations. Luxembourg: Publications Office of the European Union, 2013.

European Institute for Gender Equality. Collection of methods, tools and good practices in the field of women and media. Summary report. Luxembourg: Publications Office of the European Union, 2014.

EU Parliament. Women and girls as subjects of media attention and advertisement campaigns: the situation in Europe, best practices and legislation. Brussels: European Union, 2013.

Gallagher, M. An unfinished story: gender patterns in media employment. Paris: UNESCO, 1995.

IFJ. A handbook of gender equality best practices in the European Union. Brussels: International/European Federation of Journalists.

North, L. «Damaging and daunting: female journalists' experiences of sexual harassment in the newsroom.» Feminist Media Studies, 16(3): 495-510, 2016. http://dx.doi.org/10.1080/14680777.2015.1105275.

Ross, K. and Padovani, C. (eds.). Gender Equality and the Media: A Challenge for Europe. London, New York: Routledge, 2016, ISBN 978-1138892682.

Rush, R. R., Oukrop, C. E. and Creedon, P. J. (eds.). Seeking equity for women in journalism and mass communication education. Mahwah, NJ: Lawrence Erlbaum Associates, 2005.

Tuchman, G. "The symbolic annihilation of women by the mass media.» In Tuchman, G., Daniels, A. K. and Benét, J. (eds.), Hearth and home: images of women in the mass media. New York: Oxford University Press, 1975, 3-38. 
INTERdisciplina

www.interdisciplina.unam.mx
Volumen 7, número 17, (87-98), enero-abril 2019 D0I: http://dx.doi.org/10.22201/ceiich.24485705e.2019.17.67521

Claudia Padovani and Karen Ross

World Association for Media and Communication. Global Media Monitoring Project. Global Report. Toronto: WACC, 2015. 